\title{
Determination of corrosion and scaling levels of drinking water in distribution system: A study in Sarableh city (Ilam), western of Iran
}

\section{Heshmatollah Nourmoradi ${ }^{1}$, Seyed Ahmad Mirbagheri ${ }^{2}$, Kambiz Moradnejadi ${ }^{2}$, Faroogh} Kazembeigi $^{1}$, Mashallah Shamsizad ${ }^{2 *}$

1. Department of Environmental Health Engineering, School of Health, Ilam University of Medical Sciences, Ilam, Iran

2. Department of Environmental Engineering, School of Energy and Environment, Tehran Azad University, Branch of Sciences and Researches, Tehran, Iran

"Corresponding author: Tel: +98 8432223077; Fax: +98 8432223077

Address: Department of Environmental Engineering, School of Energy and Environment, Tehran Azad

University, Branch of Sciences and Researches, Tehran, Iran

E-mail: $\mathrm{m} \_$shamsizad@yahoo.com

Received; 2015/11/16 Revised; 2015/11/27 Accepted: 2016/01/15

\section{Abstract}

Introduction: Corrosion and scaling of water in distribution systems in spite of imposing economic and aesthetic problems can lead to adverse effects on consumers' health. The present study was conducted to evaluate the corrosion and scaling of water distribution system of Sarableh city (Ilam, Iran) during summer and winter seasons in 2014.

Materials and methods: Totally, 60 samples of water (30 samples in each season) in 30 points of the distribution system were analyzed in terms of temperature, calcium hardness, alkalinity, TDS (total dissolved solids), $\mathrm{pH}$, and DO (dissolved oxygen). Then, the corrosion and scaling of water were determined by various indices.

Results: The results of the indices showed that the quality of drinking water in Sarableh city water distribution system had a medium corrosion rate.

Conclusion: According to the results, it is needed to take some measures for stabilizing water before entering drinking water into the distribution system in order to prevent various health problems for consumers.

Key words: Water Distribution System, Corrosion, Scaling, Sarableh

\section{Introduction}

Nowadays, the limitation of drinking water resources is regarded as one of the most important challenges in urban areas, particularly in developing countries. Corrosion and scaling within drinking water distribution systems is one of the major factors which in addition to imposing some economic and aesthetic problems, it can threaten the public health of the consumers. Although, water corrosion in distribution system can enter various pollutants into the drinking water, results in health concerns (1). Many studies have shown that the major pollutants such as aluminum, antimony, arsenic, bismuth, cadmium, copper, iron, lead, nickel, selenium, tin, chloride vinyl, and zinc have been introduced the water by pipes of the distribution system (2-4). Phenomenon of scaling is one of the major problems in water distribution systems that it should be controlled due to keeping public health and increasing lifecycle of the pipes (5-7). Various studies indicated that the products resulted from corrosion of internal surfaces of pipes can be accumulated in distribution systems and protect microorganisms against the disinfectants (8). These microorganisms can proliferate and cause some problems 
such as unfavorable taste and odor, biological masses and subsequently increasing corrosion $(6,9)$. Water stability leads to prevent corrosion and scaling in the water distribution systems (10). Various factors including pipe type, concentration of dissolved oxygen, sulfate, carbon dioxide and chemical disinfectant, temperature and the existence of microorganisms in water affect on the corrosion level in water distribution systems (11). Many procedures such as Langelier saturation index (LI), Ryznar stability index (RI), Aggressive index (AI) and Puckorius index (PI) have been extensively used to determine the corrosion and scaling of water (11). In this study, the corrosion and scaling of water in the distribution system of Sarableh city (Ilam, Iran) was determined by abovementioned tests.

\section{Materials and methods}

The present study was carried out upon drinking water in distribution system of Sarableh city (Iran) during two warm (summer) and cold (winter) seasons in 2014. Sarableh city (with coordinate of $33^{\circ} 46^{\prime} \mathrm{N} 46^{\circ} 33^{\prime} 59^{\prime \prime} \mathrm{E}$ ) is placed in Ilam province, western of Iran. At the 2011 census, the population of Sarableh city was 13,000 people. The drinking water sources in this city are provided by 3 semi-deep wells with flow rate of $94 \mathrm{~L} / \mathrm{s}$. The water network in this city is branched type that the pipelines in the system have been made of galvanized iron, asbestos and polyethylene. For conducting this study, firstly, the sampling points were selected all over the network, so that the sampling stations covered all the distribution system. Figure 1 shows the location of Sarableh city in Iran and also shows the water sampling points in this study.

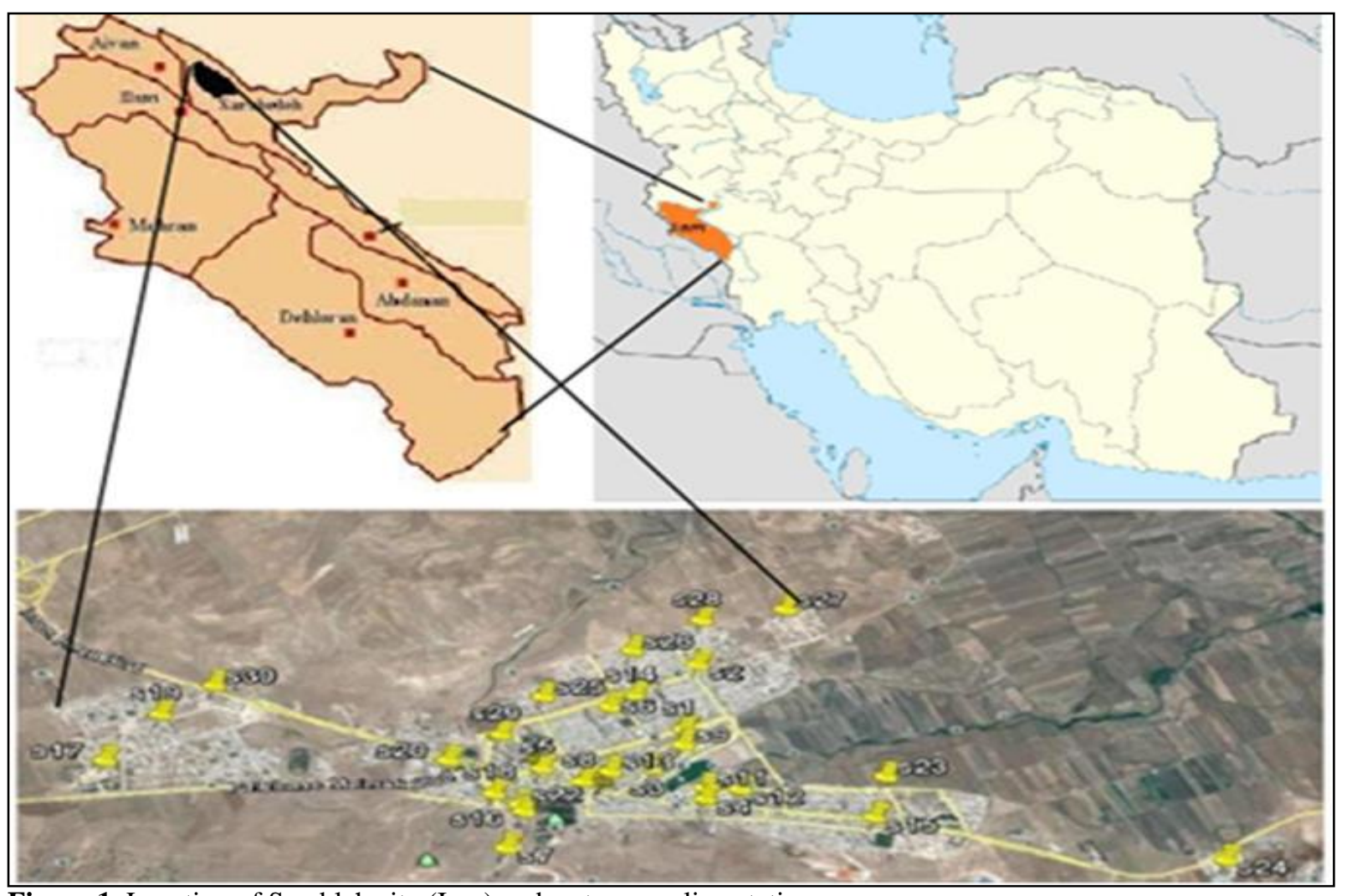

Figure 1. Location of Sarableh city (Iran) and water sampling stations.

Water sampling and analysis: According to the USEPA regulations, 30 sampling points should be considered in water distribution system covered 13000 peoples (12). Therefore, 30 stations were selected to take the water samples. Water sampling 
was conducted during the warm and cold seasons in 2014. For each station, $500 \mathrm{~mL}$ of water was picked up and temperature, electrical conductivity (EC) and $\mathrm{pH}$ of it were measured in-situ. Other parameters including calcium hardness, alkalinity and total dissolved solids (TDS) were also measured in water laboratory. All the parameters were measured according the standard methods (13). The scaling and corrosion of water were then calculated by Langelier, Ryznar, Aggressive and Puckorius indices. Eq. 1 to Eq. 6 can be used to determine the Lengelier index (LI).

$$
\begin{aligned}
& \mathrm{LI}=\mathrm{pH}-\mathrm{pH}_{s} \\
& \mathrm{pH}_{\mathrm{g}}=(9.3+\mathrm{A}+\mathrm{B})-(\mathrm{C}+\mathrm{D}) \\
& A=\frac{(\log 10(T D S)-1)}{10} \\
& B=-13.12 \log _{10}(C+273)+34.5 \\
& \mathrm{C}=\mathrm{Log}_{10}\left(\mathrm{Ca}^{+2} \text { as } \mathrm{CaCO}_{3}\right)-0.4 \\
& \mathrm{~A}=\frac{\log _{10} \text { (Total Alkalinity) }}{10}
\end{aligned}
$$

where $\mathrm{pH}$ and $\mathrm{pHs}$ are the actual $\mathrm{pH}$ of water and $\mathrm{pH}_{\mathrm{S}}$ in the saturation state with calcium carbonate, respectively. $\mathrm{A}$ is the concentration of TDS of water $(\mathrm{mg} / \mathrm{L})$. B is the temperature of water $\left({ }^{\circ} \mathrm{C}\right.$ or $\left.{ }^{\circ} \mathrm{F}\right) . \mathrm{C}$ and $\mathrm{D}$ also are calcium hardness $(\mathrm{mg} / \mathrm{L}$ $\left.\mathrm{CaCO}_{3}\right)$ and Alkalinity $\left(\mathrm{mg} / \mathrm{L} \mathrm{CaCO}_{3}\right)$ of water, respectively (11). Ryznar index (RI) or Stability index (SI) is calculated by Eq. 7. The values of $\mathrm{pHs}$ can be achieved by Eq. 2 to Eq. 6.

RI or SI $=2 \mathrm{pH}_{\mathrm{s}}-\mathrm{pH}$

Eq. 8 can be used to determine Aggressive index (AI).

$\mathrm{AI}=\mathrm{pH}+\log [(\mathrm{A})(\mathrm{H})]$

where $\mathrm{A}$ and $\mathrm{H}$ are alkalinity $(\mathrm{mg} / \mathrm{L}$ $\left.\mathrm{CaCO}_{3}\right)$ and calcium hardness $(\mathrm{mg} / \mathrm{L}$ $\mathrm{CaCO}_{3}$ ) of water sample, respectively. Puckorius index (PI) is also determined by the following equations.

$$
\begin{aligned}
& \mathrm{PI}=2 \mathrm{pH}_{\mathrm{s}}-\mathrm{pH}_{\mathrm{eq}} \\
& \mathrm{pH}_{\mathrm{eq}}=1.465 \log _{10}(\mathrm{~T} \mathrm{Alk})+4.54
\end{aligned}
$$

where $\mathrm{pH}_{\text {eq }}$ refers to water $\mathrm{pH}$ at equilibrium state and $\mathrm{T}$ Alk is alkalinity $\left(\mathrm{mg} / \mathrm{L} \mathrm{CaCO}_{3}\right)$ of water (11). Table 1 shows the relation between the abovementioned indices and water quality.

Table 1. The quality of water in terms of scaling and corrosion through various indices.

\begin{tabular}{lll}
\hline Index Type & Index value & Water property \\
\hline Lengelier index (LI) & $\mathrm{LI}>0$ & Scale can form \\
& $\mathrm{LI}=0$ & Stable water \\
& $\mathrm{LI}<0$ & Water is corrosive \\
\hline Ryznar index (RI) or Stability & $<4$ & High level of scaling \\
index (SI) & $4-6$ & Relatively scaling and slightly corrosive \\
& $6-6.5$ & Neither corrosive nor scaling \\
& $6.5-7$ & Corrosive property and low level of scaling \\
& $>8$ & Severely corrosive \\
\hline Aggressive index (AI) & $<10$ & Very aggressive \\
& $10-12$ & Moderately aggressive \\
\hline Puckorius index (PI) & $>12$ & Non-aggressive \\
\hline
\end{tabular}

\section{Results}

The results of the various quality parameters of drinking water in Sarableh city are presented in Table 1 . Table 2 also shows the results of the various corrosion and scaling indices. Figures 2 and 3 show the values of the indices in different sampling stations of the distribution system. 
Table 2. The values of measured parameters in water distribution system of Sarableh city.

\begin{tabular}{lcccccccc}
\hline Season & $\begin{array}{c}\text { Alkalinity } \\
(\mathrm{mg} / \mathrm{L} \text { CaCO3 })\end{array}$ & $\begin{array}{c}\text { TDS } \\
(\mathrm{mg} / \mathrm{L})\end{array}$ & $\begin{array}{c}\mathbf{C a}^{++} \\
(\mathrm{mg} / \mathrm{L})\end{array}$ & $\mathbf{p H}$ & $\mathbf{p H s}$ & $\begin{array}{c}\text { DO } \\
(\mathrm{mg} / \mathrm{L})\end{array}$ & $\begin{array}{c}\text { EC } \\
(\mu \mathrm{s} / \mathrm{cm})\end{array}$ & $\begin{array}{c}\text { Temperature } \\
\left({ }^{\circ} \mathrm{C}\right)\end{array}$ \\
\hline Winter & 220 & 333 & 61 & 7.45 & 7.88 & 6.88 & 521.5 & 15.2 \\
Summer & 214 & 293 & 62 & 7.50 & 7.67 & 6.29 & 459.5 & 26.0 \\
\hline
\end{tabular}

Table 3. The values of corrosion and scaling indices in water distribution system of Sarableh.

\begin{tabular}{lcccc}
\hline \multirow{2}{*}{ Season } & \multicolumn{4}{c}{ Indices } \\
\cline { 2 - 5 } & Langelier $(\mathrm{LI})$ & Ryznar $(\mathrm{RI})$ & Puckorius index $(\mathrm{PI})$ & Corrosion index $(\mathrm{AI})$ \\
\hline Winter & -0.42 & 8.25 & 7.75 & 11.64 \\
Summer & -0.18 & 7.85 & 7.38 & 11.59 \\
\hline
\end{tabular}
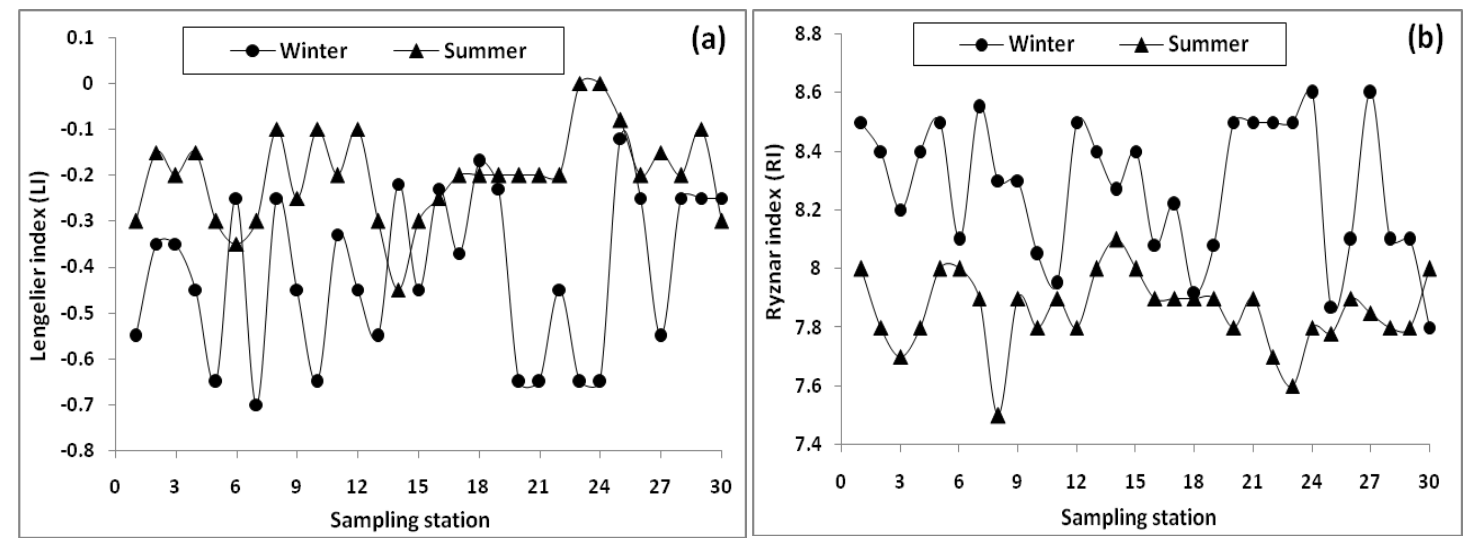

Figure 2. (a) Lengelier and (b) Ryznar indices for drinking water of Sarableh city.
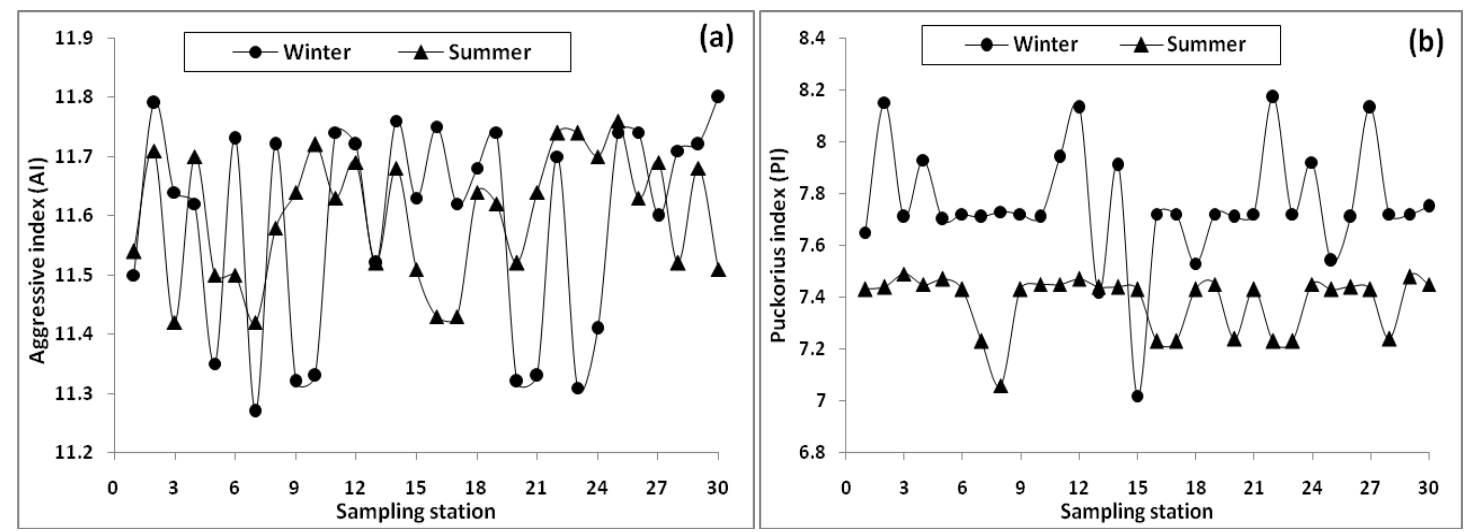

Figure 3. (a) Aggressive and (b) Puckorius indices for drinking water of Sarableh city.

\section{Discussion}

Physiochemical quality of water is one of the most important factors in appearing corrosion and scaling. Waters with high concentration of oxygen, TDS, temperature and residual chlorine can cause water corrosion and scaling (10). The entrance of various compounds such as lead, copper, cadmium, nickel, selenium, tin etc resulted from corrosion of internal surface of pipes into the water can lead to adverse effects on the human health. Previous studies indicated that toxicity by lead can cause mental retardation in children, anemia, make people feel headache, muscle aches, general fatigue and anger. Lead may be entered into drinking water through pipes, bronze and brass fittings of distribution systems (15). A study by Edwards (2008) showed that using lead containing drinking 
water by pregnant women can lead to higher concentration of lead in their blood and subsequently their babies' blood, especially when they consumed water from water pipes that have not been used for a while (16). The presence of copper in drinking water accelerates corrosion of galvanized iron and steel coverings which resulted in unfavorable health effects on human (13). A study by Teimouri et al. (2012) showed that the corrosion state of water in distribution system of Kian city, Iran was in medium to high and the corrosion in this city in winter was higher than of summer (17). Nawrocki et al. (2010) study upon corrosion of stagnant waters within distribution network indicated that the phenomenon of nitrification in stagnant waters can provide a favorable environment for growth of sulfate-reducing bacteria. They observed these bacteria in all samples of stagnant waters (18). Dargahi et al. (2014) study on water distribution system of Kermanshah city, Iran showed that the average of Langelier and Ryznar indices was -0.28 and 7.57, respectively. Therefore, it can be concluded that water of Kermanshah city was corrosive (19). A study by Pasban et al. (2013) on the corrosion and scaling potential of drinking water in distribution system of Bojnourd city, Iran indicated that the average values of Ryznar and Langelier indices during two seasons of winter and spring have significant difference. They also reported that water in distribution system of Bojnourd city was relatively scaling (20). The results of water quality parameters in Sarableh city indicted that the water temperature changed depending on plumbing conditions, the sampling time, environmental temperature and sampling place, so that, the water temperature within Sarableh distribution network was varied from $12.5-20.5^{\circ} \mathrm{C}$ (mean of $15.2^{\circ} \mathrm{C}$ ) and 23.0-28.2 ${ }^{\circ} \mathrm{C}$ (mean of $26.0{ }^{\circ} \mathrm{C}$ ) during winter and summer, respectively. The values of $\mathrm{pH}$ (7.45 to 7.5$)$ during the study were in accordance with the standards and the amount of it was negligibly increased from the beginning to ending the distribution system. The value of $\mathrm{pH}$ in Sarableh city in summer was partially higher than winter. The average of TDS concentration and alkalinity in winter was higher than of summer in this study. So that, the values of TDS and alkalinity were $333 \mathrm{mg} / \mathrm{L}$ and $220 \mathrm{mg} / \mathrm{L} \mathrm{CaCO}_{3}$ and 293 $\mathrm{mg} / \mathrm{L}$ and $214 \mathrm{mg} / \mathrm{L} \mathrm{CaCO}_{3}$ in winter and summer, respectively. The mean of dissolved oxygen concentration in distribution network of Sarableh city also was higher in winter $(6.88 \mathrm{mg} / \mathrm{L})$ toward summer $(6.88 \mathrm{mg} / \mathrm{L})$. This can be due to that the solubility of gases such as oxygen which higher in colder seasons. The results of measuring the various water quality parameters including temperature, DO, calcium hardness, Alkalinity, electricity conductivity and TDS showed that all the above parameters were in accordance with the WHO drinking water guidelines and also national (Iran) standards. The values of Langelier (-0.18 to -0.42), Ryznar (7.85 to 8.25$)$, corrosion (11.59 to 11.64 ) and Puckorius (7.38 to 7.75) indices for water distribution system in Sarableh city showed that drinking water in Sarableh city was corrosive.

\section{Conclusion}

The results showed that the corrosion indices in drinking water of Sarableh city was in middle state. The amount of corrosion in winter season also was higher than of summer. In order to prevent the entrance of adverse compounds including lead, cadmium, copper, zinc, magnesium, iron etc into the drinking, it is necessary to conduct some proper measurements including water $\mathrm{pH}$ regulation etc by authorities with the aim of controlling water corrosion. 


\section{References}

1. Rezaee Kalantari R, Yari AR, Azari A, Ahmadic E, Azari A, et al. Survey of corrosion and scaling potential in drinking water resources of the villages in Qom province by use of four stability indexes (with quantitative and qualitative analysis). Arch Hyg Sci. 2013;2(4):127-34.

2. ASTM. Standard test methods for corrosivity of water in the Absence of heat transfer. 1994. Designation: D2688-92.

3. Jafari MA, Fallah F, Hassani AH. Investigating the hygiene of anzali drinking water resources for corrosion and precipitation potentials using corrosion indexes. J Guilan Univ Med Sci. 2011;20(79):90-6.

4. Shahmansoori M, Pourmoghadas H, Shams G. Survey of Micro Pollutant of Pipes Corrosion in the Water Distribution System. J Res Med Sci. 2008;8(2): 1-7.

5. Davil M, Mahvi A, Norouzi M, Amarloei A, Mazloomi S. Survey of corrosion and scaling potential produced water from Ilam water treatment plant. World Appl Sci J. 2009;7(11):11-24.

6. Dehghani M, Tex F, Zamanian Z. Assessment of the potential of scale formation and corrosivity of tap water resources and the network distribution system in Shiraz, South Iran. Pak J Biol Sci. 2010;15;13(2):88-94.

7. Nabizadeh Nodehi R, Fezi Razi D. the guideline of Drinking Water quality. 2nd ed. Tehran: The cultural Physicals Organization; 2006. 34-39.

8. Geldreich E. Microbial quality of Water suply in distribution System. Florida: CRC press; 2012.

9. Schock MR. Internal corrosion and deposition control. In Association AWW (Ed) Water Quality and Treatment: A Handbook of Community Water Supplies. 1999. Philadelphia; Mcgraw-Hill. 1-17.
10. Hosseinian M, Mirsadeghi J. Corrosion and its control within water distribution systems. J Water Environ. 1998;28(1):1-8.

11. Hoseinzadeh E, Yusefzadeh A, Rahimi $N$, Khorsandi $H$. Evaluation of corrosion and scaling potential of a water treatment plant. Arch Hyg Sci. 2013;2(2):41-7.

12. Davis CE. Economic analyses at EPA: Assessing regulatory impact: Edited by Richard D. Morgenstern Washington, DC: Resources for the Future, 1997.

13. American Public Health Association (APHA). Standard Methods for the Examination of Water and Wastewater. 21st Ed. Washington DC. 2005.

14. Rostami, A, Najafi, M. Investigation on corrosion and scaling potential of Shahre kord drinking water resources. $16^{\text {th }}$ National Congress of Environmental Health. 2013.

15. World Health Organization, Guidelines for Drinking-Water Quality: World Health Organization, Distribution and Sales, Geneva 27, CH-1211 Switzerland, 2004.

16. Edwards M. Controlling corrosion in drinking water distribution systems: a grand challenge for the 21 st century. Water Sci Technol. 2004; 49(2):1-8.

17. Teimouri F, Sadeghi M, Dress F, Hashemi H, Shakeri K, Rezaei S. Survey of Corrosion or Scaling Potential of Resources, Storage and Distribution of Wate Supply System in Kian by using Langlier and Rizne Indexes. Health Sys Res. 2012; 8(1):78-84.

18. Nawrocki J, Raczyk-Stanisławiak U, Świetlik J, Olejnik A, Sroka MJ. Corrosion in a distribution system: Steady water and its composition. Water Res. 2010;31;44(6):1863-72.

19. Dargahi A, Maleki P, Gholizadeh F, Jedi Z. Investigation on water corrosion and scaling in Kermanshah distribution system. $6^{\text {th }}$ student 
congress, Ardebil University of Medical Sciences. 2014.

20. Pasban A, Attamaleki A. Yanigh A, Ghorbanpour R, Tourkanlo H. Survey on corrosion and scaling potential of drinking water in water distribution system in Bojnourd 2011-2012. $8^{\text {th }}$ Student National Conference Environmental Health of Iran. 2013. 